\title{
Vital Capacity Abnormal, CTCAE
}

National Cancer Institute

\section{Source}

National Cancer Institute. Vital Capacity Abnormal, CT CAE. NCI Thesaurus. Code C143939.

A finding based on pulmonary function test results that indicate an abnormal vital capacity (amount of exhaled after a maximum inhalation) when compared to the predicted value. 